\title{
Verificação da contaminação por dimetoato e aldicarb em fígado de tilápias do Nilo (Oreochromis niloticus) coletados em dois frigoríficos do Estado do Paraná
}

\section{Verification of contamination by dimetoato and aldicarb in liver of Nile tilapias (Oreochromis niloticus) collected in two cold-storages in the State of Paraná}

\author{
Mari Sylmara Martins Rodrigues ${ }^{1 *}$; Cristina Arduini Cavalcanti de Arruda ${ }^{2}$; \\ Daisy Pontes Netto ${ }^{3}$; Alexandre Nabuhiro Tajiri ${ }^{4}$
}

\section{Resumo}

\begin{abstract}
A importância dos peixes como fonte protéica na alimentação humana é indiscutível, porém seu papel como indicador de contaminação ambiental também é muito relevante. O presente trabalho objetivou a análise de fígados de Tilápia do Nilo (Oreochromis niloticus), coletados em frigoríficos comerciais de dois municípios do Estado do Paraná para averiguação de contaminação pelos compostos organofosforados e carbamatos. Coletou-se 30 amostras de fígado de Tilápia do Nilo (O. niloticus) no frigorífico A e 45 amostras no frigorífico B, totalizando 75 amostras analisadas. Em cada local foram realizadas três visitas, e de forma aleatória, coletadas as amostras no período de julho de 2006 a maio de 2007. Para extração e análise das amostras utilizou-se a metodologia qualitativa de Cromatografia em Camada Delgada (CCD). Os padrões de organofosforado e carbamato utilizados na análise de CDD foram respectivamente o Dimetoato e Aldicarb. Nas amostras analisadas foi encontrado o praguicida cabarmato em sete amostras, sendo uma das amostras coletada no frigorífico A e seis coletadas no frigorífico B. O composto organofosforado foi encontrado em quinze amostras das 75 amostras analisadas, sendo sete amostras do frigorífico A e oito das amostras do frigorífico B. Os resultados obtidos inferem na possibilidade da contaminação dos tanques de criação nas pisciculturas e da necessidade de monitoramento constante quanto à presença de resíduos de praguicidas nesta importante matriz alimentícia.
\end{abstract}

Palavras-chave: Dimetoato., aldicarb, fígado, Tilápia do Nilo (Oreochromis niloticus)

\begin{abstract}
The importance of fish as a protein source in food is unquestionable, but its role as an indicator of environmental contamination is also very important. This study aimed to analysis the livers of Nile tilapia (Oreochromis niloticus), collected from commercial cold-storages in two municipal districts in the State of Parana, for investigation of contamination by organophosphorus compounds and carbamates. It was collected 30 samples of Nile tilapias (O. niloticus) liver in the cold-storage A and 45 samples in the cold-storage B, totaling 75 samples. At each location were three visits, and at random, collected the samples from July 2006 to May 2007. For extraction and analysis of samples it was used the qualitative
\end{abstract}

\footnotetext{
1 Graduanda em Medicina Veterinária pela Universidade Estadual de Londrina . Bolsista IC/UEL. E-mail: vet_mari@hotmail. com.

2 Graduanda em Medicina Veterinária pela Universidade Estadual de Londrina (UEL). Bolsista PIBIQ/CNPq .

3 Professora Associada, Doutora. Universidade Estadual de Londrina (UEL), CCA/Depto. de Medicina Veterinária Preventiva.

4 Mestrando em Medicina Veterinária pela Universidade Estadual de Londrina (UEL).

* Autor para correspondência.
} 
methodology of Thin Layer Chromatography (TLC). Patterns of organophosphate and carbamate used in the analysis of the TLC were respectively Dimethoate and Aldicarb. Of the samples tested were found cabarmate in seven samples, one of the samples collected in the cold-storage A and six collected in the cold-storage B. The organophosphate compound was found in fifteen samples from 75 samples, seven of the cold-storage A and eight samples from the cold-storage B. The results infer the possibility of contamination of the tanks in the creation of farms and the need for constant monitoring for the presence of residues of pesticides in this important food matrix.

Key words: Dimethoate, aldicarb, liver. Nile tilapias (Oreochromis niloticus)

\section{Introdução}

A contaminação das águas é um tema que atualmente preocupa o mundo. $\mathrm{O}$ uso indiscriminado de praguicidas vem durante anos contaminando rios e lençóis freáticos. Esta contaminação está presente também nas pisciculturas, em que as águas das chuvas carregam compostos usados para controle de pragas em lavouras e em criações animais, levando assim à contaminação dos tanques onde são criados os peixes.

Outras formas de contaminação destas pisciculturas são: volatilização dos compostos aplicados nos cultivos, formação de poeira do solo contaminado e pulverização de praguicidas, que podem ser transportados por correntes aéreas sofrendo depósito no solo e na água, distantes das áreas onde foram originalmente aplicados (ARIAS et al., 2007).

A importância dos peixes como fonte protéica na alimentação humana é indiscutível, porém seu papel como indicador de contaminação ambiental também é muito relevante (STREIT, 1998). Segundo GirónPérez et al. (2007), a Tilápia do Nilo (Oreochromis niloticus) é um ótimo modelo para avaliação do ecossistema aquático e para realização de estudos toxicológicos. Os peixes como um todo são excelentes para este tipo de estudo, pois possuem a capacidade de retirar, estocar e bioacumular compostos poluentes em seus organismos (STREIT, 1998).

Os primeiros locais de captação dos poluentes presentes nas águas são as brânquias, portanto, os primeiros efeitos da substância química vão ser observados nestes órgãos (SANCHO apud GIRÓNPÉREZ et al. 2007), o fígado recebe o volume de sangue previamente filtrado por estas estruturas e possui importância extrema na desintoxicação e eliminação da substância do organismo (GIRÓNPÉREZ et al., 2007).

Os compostos organofosforado e carbamato agem bloqueando irreversivelmente a ação da acetilcolinesterase sobre a acetilcolina, evitando a hidrólise deste neurotransmissor, resultando em paralisia espástica e conseqüente eliminação do parasita (SARTOR; SANTARÉM, 2006).

Os organosfosforados foram originalmente introduzidos como praguicidas pelos cientistas alemães antes e durante a Segunda Guerra Mundial (SARTOR; SANTARÉM, 2006). Acredita-se que estes compostos foram introduzidos como uma alternativa aos organoclorados, que apresentam uma maior bioacumulação (GIRÓN-PÉREZ et al., 2007). Atingiram uso indiscriminado como antihelmíntico e praguicida, uma vez que são altamente tóxicos para diversos parasitas.

Segundo Dutta e Arends (2003), a inibição da acetilcolinesterase leva a alterações de comportamento em animais de laboratório. No meio aquático natural, a inibição da atividade desta enzima pode afetar drasticamente uma série de fatores como: crescimento, sobrevivência, alimentação, e comportamento reprodutivo (DUTTA; ARENDS, 2003). Existem evidências de que este composto possui ação cancerígena quando administrado em animais de experimento (ADAMS, 1992).

Vários fatores estão envolvidos na alteração de atividade da acetilcolinesterase pelos organofosforados, como a duração do período de exposição e concentração do agente (ÜNER et al., 2006). 
Os carbamatos possuem grau variado de toxicidade para o ser humano. São utilizados como inseticidas, fungicidas e parasiticidas na agricultura (SARTOR; SANTARÉM, 2006).

Estudos estão sendo realizados a respeito da toxicidade do carbofuran, inseticida da classe dos carbamatos, na vida aquática (ELSER; KIMMEL, 1985; HEJDUK; SVOBODOVA, 1980). Animais envenenados apresentam um aumento na atividade metabólica associado a um aumento do estresse, que juntos vão levar a uma depleção da reserva de energia do organismo (DUTRA; FERNANDES; OLIVEIRA, 2008).

Este trabalho possui um caráter inédito no estado do Paraná, Brasil, pois se propôs a analisar os filés de tilápia provenientes de frigoríficos, adotando assim uma postura de vigilância da qualidade do alimento que chega à população.

O trabalho objetivou a investigação da contaminação de fígados de Tilápia do Nilo ( $O$. niloticus), coletados em frigoríficos comerciais de dois municípios do Estado do Paraná, por compostos organofosforados e carbamatos.

\section{Material e métodos}

\section{Locais de coleta e amostragem}

As coletas foram realizadas em dois frigoríficos de peixe do Estado do Paraná/Brasil, contatados pela Secretaria da Agricultura e Abastecimento do Paraná (SEAB), órgão governamental que fiscaliza e regulamenta as atividades rurais, agrícolas e pecuárias no Estado. Ambos frigoríficos trabalham apenas com peixes provenientes de piscicultura comercial.

Os frigoríficos foram escolhidos pela importância econômica que exercem em seus locais de atuação e serão designados pelas letras A e B. O frigorífico A localiza-se na região Oeste do Estado do Paraná e possui serviço de inspeção federal (SIF). O frigorífico B localiza-se na região Norte do estado do Paraná e possui serviço de inspeção municipal (SIM). O frigorífico A possui uma média de abate semanal de 30 toneladas, e o frigorífico B uma média semanal de 600-1000 Kg.

Coletou-se 30 amostras de fígado de Tilápia do Nilo (O. niloticus) no frigorífico A e 45 amostras no frigorífico $\mathrm{B}$, totalizando 75 amostras analisadas.

Foram realizadas duas visitas no frigorífico A e três visitas no frigorífico $\mathrm{B}$, com a coleta de 15 amostras de filé de tilápia em cada uma, de forma aleatória, na fase final do processamento, antes da fase de embalagem. O período de coleta estendeu-se de julho de 2006 a maio de 2007.

\section{Protocolos de coleta}

As amostras foram acondicionadas em sacos plásticos e mantidas refrigeradas, em bolsas térmicas, do local de coleta até o laboratório.

Antes da estocagem e análises, os fígados foram pesados e cerca de $50 \mathrm{~g}$ foi separado como amostra. As amostras foram re-embaladas em filme de PVC, numeradas e congeladas a $-20^{\circ} \mathrm{C}$.

\section{Análise do material}

As análises foram feitas no Laboratório de Toxicologia Veterinária e Plantas Tóxicas (Departamento de Medicina Veterinária Preventiva da Universidade Estadual de Londrina), no período de 10/03/2008 à 05/05/2008.

\section{Metodologia analítica}

Para extração e análise das amostras utilizouse a metodologia qualitativa de Cromatografia em Camada Delgada (CCD) (MARTINEZ-VIDAL et al., 1997; MINELI; RIBEIRO, 1996; MORAES, 1991). 
1 - Padrões e reagentes utilizados:

Os padrões de organofosforado e carbamato utilizados naanálise de CDD foramrespectivamenteo Dimetoato (fosforoditioato de S-(N-metilcarbamoilmetil)-O,O-dimetilditiofosforilacetico)

Aldicarb ([2-metil-2-(metiltio) propionaldeido O-(metilcarbamoil)oxima]).

A concentração do padrão de Dimetoato para análise em CDD foi de $100 \mu \mathrm{g} / \mathrm{ml}$ diluído em acetona. Para preparação do padrão de Aldicarb foi utilizado acetonitrila com ressuspensão em N-hexano e utilizado na concentração de $100 \mu \mathrm{g} / \mathrm{ml}$.

Os reagentes utilizados foram o sulfato de sódio anidro P.A $\left(\mathrm{NaSO}_{4}\right)$ diluído a $30 \%$, corante rodamina preparado a partir da mistura de 0,4 gramas de rodamina $\left(\mathrm{C}_{28} \mathrm{H}_{31} \mathrm{CIN}_{2} \mathrm{O}_{3}\right), 100 \mathrm{ml}$ de ácido clorídrico (HCL) $1 \mathrm{~N}$ e $10 \mathrm{ml}$ de nitrato de prata $\left(\mathrm{AgNO}_{3}\right) \quad 0,02 \mathrm{~N}$; corante p-nitroanilina preparado a partir da mistura das soluções A e B. Solução A: 1 grama de p-nitroanilina $\left(\mathrm{C}_{6} \mathrm{H}_{6} \mathrm{~N}_{2} \mathrm{O}_{2}\right)$ diluídos em $100 \mathrm{ml}$ de ácido clorídrico. Solução B: nitrito de sódio $\left(\mathrm{NaNO}_{2}\right)$ P.A. a 3\% diluídos em $100 \mathrm{ml}$ de água destilada. Corante hidróxido de sódio $(\mathrm{NaOH})$ diluído a $40 \%$ diluído em proporções iguais de etanol $\left(\mathrm{C}_{2} \mathrm{H}_{5} \mathrm{OH}\right)$.

2 - Extração de resíduos de Dimetoato e Aldicarb para análise em CDD:

A extração e purificação dos resíduos de Dimetoato a Aldicarb para análise em CCD foram realizadas colocando-se em um erlenmeyer de $250 \mathrm{ml}, 5 \mathrm{~g}$ da sub-amostra, $5 \mathrm{ml}$ de água destilada, 0,5ml de ácido fórmico P.A. $98-100 \%\left(\mathrm{CH}_{2} \mathrm{O}_{2}\right), 2 \mathrm{ml}$ de sulfato de sódio $30 \%$ e $30 \mathrm{ml}$ de acetonitrila P.A. $\left(\mathrm{CH}_{3} \mathrm{CN}\right)$. Agitou-se por 10 minutos em aparelho Agitador Kline modelo 255 e posteriormente foi realizada a centrifugação em aparelho Presvac DCS16-RV a 2000rpm por 10 minutos. Em um funil de separação de $250 \mathrm{ml}$ foi colocado o sobrenadante e extraído 2 vezes com $20 \mathrm{ml}$ de N-hexano P.A., desprezando-se a fase de acetonitrila P.A. $\left(\mathrm{CH}_{3} \mathrm{CN}\right)$.
A fase do N-hexano P.A. foi filtrado utilizando-se papel filtro e sulfato de sódio anidro P.A. $\left(\mathrm{NaSO}_{4}\right)$. Após evaporação, o material seco da sub-amostra sofreu re-suspensão com $2 \mathrm{ml}$ de N-hexano P.A., homogeneizado e com utilização de tubos capilares de $75 \mathrm{~mm}$, diâmetro interno $1,0 \mathrm{~mm}$ e externo $1,5 \mathrm{~mm}$ para determinação de micro-hematócrito sem heparina, aplicou-se 15 gotas do material ressuspenso em placas de $0,25 \mathrm{~mm}$ de espessura de sílica gel preparadas previamente com 5 gramas de sílica gel $60 \mathrm{G}$ diluídos em $10 \mathrm{ml}$ de água destilada. Posteriormente a placa de sílica gel 60G Mesh foi colocada em uma cuba para cromatografia previamente saturada com solução de clorofórmio P.A.; acetona P.A. $(70 \mathrm{ml}: 30 \mathrm{ml})$, removida após atingir $80 \%$ de desenvolvimento e secagem em temperatura ambiente.

3 - Identificação de resíduos de Dimetoato e aldicarb pela CCD:

A leitura para presença de resíduos de Dimetoato foi realizada após utilização do corante rodamina. Para leitura da presença de resíduos de Aldicarb utilizou-se o corante p-nitroanilina e em seguida a placa foi mantida em estufa a temperatura de $50^{\circ} \mathrm{C}$ por 5 minutos. Após o resfriamento da placa utilizou-se hidróxido de sódio $40 \%$.

\section{Resultados e discussão}

Os peixes sofrem contaminação pela ingestão de alimentos que contém partículas tóxicas, ou pelo contato com o contaminante que está presente na água. Quando o seqüestro se dá apenas pela retirada do contaminante do meio pelo contato temos a bioconcentração, porém quando a retirada do contaminante se dá pelas duas vias temos a bioacumulação (STREIT, 1998).

$\mathrm{Na}$ bioconcentração a substância tóxica penetra no organismo, principalmente, pelas brânquias e pelos outros tecidos que estão em contato direto 
com o meio, fatores físicos e ambientais interferem neste parâmetro (STREIT, 1998).

No presente trabalho, do total de amostras analisadas foi encontrado carbamato em sete amostras, sendo uma do frigorífico A e seis do frigorífico B. (Tabela. 1). O composto organofosforado foi encontrado em quinze amostras, sendo sete do frigorífico A e oito do frigorífico B (Tabela. 1). Portanto, das 75 amostras analisadas $9,3 \%$ estavam contaminadas pelo praguicida carbamato, enquanto $20,0 \%$ estavam contaminadas por compostos organofosforados (Tabela. 1).

Tabela 1. Resultados das análises das amostras provenientes do frigorífico A ( 30 amostras) e frigorífico B (45 amostras) dos princípios ativos carbamato e organofosforado, coletadas no período de julho de 2006 a maio de 2007, e as respectivas porcentagens de amostras positivas.

\begin{tabular}{|c|c|c|c|c|c|c|c|}
\hline & \multicolumn{3}{|c|}{ Frigorífico A } & \multicolumn{3}{|c|}{ Frigorífico B } & \multirow{2}{*}{ Total } \\
\hline & $\mathrm{N}$ & $\mathrm{P}$ & $\%$ de positivos & $\mathrm{N}$ & $\mathrm{P}$ & $\%$ de positivos & \\
\hline Carb & 29 & 01 & 3,3 & 39 & 06 & 13,3 & 75 \\
\hline Org & 23 & 07 & 23,3 & 37 & 08 & 17,8 & 75 \\
\hline Total & 52 & 08 & 15,9 & 76 & 14 & 18,4 & 150 \\
\hline
\end{tabular}

N: negativo; P: positivo; Carb: carbamato; Org: organofosforado

Os dados acima demonstram que peixes criados em pisciculturas comerciais não estão livres da contaminação das águas por praguicidas, que são levados aos tanques presuntivamente do mesmo modo que são levados às águas dos rios, onde contaminam os cardumes nele existentes. Apresença destes compostos nos rios pode ocorrer pela volatilização, transporte atmosférico e precipitações (RACKE, 1992; BIDLEMAN, 1999; VAN DIJK; GUICHERIT, 1999), sendo importantes meios de contaminação no período de baixa pluviosidade ou pelas lixiviações em solos tratados com estas substâncias.

As regiões onde se localizam os frigoríficos estudados nesta pesquisa são historicamente conhecidas como áreas de grande produção agropecuária, onde é freqüente o uso dos compostos organofosforado e carbamato para o controle de pragas nas lavouras e como antiparasitários nas criações de animais. Este fato reforça a possibilidade destes compostos serem levados aos tanques de criação por águas pluviais contaminadas.

Soumis et al. (2003), pesquisando a presença de inseticidas organofosforados em peixes do rio
Amazonas, observou que os níveis encontrados apresentaram-se abaixo das ingestão diária aceitável (IDA) para o consumo humano. Vale salientar que as concentrações observadas pelo autor foram encontradas em animais que vivem em água corrente, o que não ocorre nos tanques de criação das pisciculturas onde os princípios podem se concentrar.

Os praguicidas são absorvidos e carreados ao fígado, local onde pelas enzimas irá ocorrer a bioativação e desintoxicação destes compostos. A mensuração da atividade de enzimas hepáticas como ALT, ALP e GGT no soro ou plasma, é utilizada rotineiramente para verificar a presença de alterações bioquímicas da função deste órgão causada por diferentes agentes tóxicos (GIRÓNPÉREZ et al., 2007).

Em um experimento realizado com Tilápias do Nilo (O. niloticus), em que estas sofreram exposição ao diazinon (7.830ppm e $3.915 \mathrm{ppm}$ ) por 96 horas, não existiu diferença estatística $(p \square 0,05)$ quando comparado com o grupo controle em relação às enzimas hepáticas acima citadas (GIRÓN-PÉREZ et al., 2007). 
Durmaz, Sevgiler e Üner (2006) verificou a presença de alterações na atividade de enzimas anti-oxidantes e também da acetilcolinesterase em Tilápias do Nilo (O. niloticus) expostas ao diazinon. A metodologia utilizada no estudo foi a espectofotometria, realizada em brânquias, rins, trato alimentare tecido muscular. Diferenças significativas foram encontradas nos diferentes tecidos, o que indica a existência de uma grande especificidade tecidual e dependência da dose utilizada durante a exposição dos animais ao composto.

Assim como nos peixes, alterações em decorrência de exposição aos praguicidas podem estar presentes em outros animais aquáticos, como por exemplo, em crustáceos. Dutra, Fernandes e Oliveira (2008) verificou os efeitos do carbofuran no metabolismo energético, atividade da $\mathrm{Na}^{+}$/ $\mathrm{K}^{+}$ATPase e alguns parâmetros reprodutivos de crustáceas do gênero Hyalella (Hyalella pleoacuta e Hyalella curvispina).

Os animais foram expostos a doses de 5 ou $50 \mu \mathrm{g} / \mathrm{L}$, por um período de 7 dias, ao final deste período, os animais foram congelados para determinação dos parâmetros bioquímicos, mensuração da atividade da enzima $\mathrm{Na}^{+} / \mathrm{K}^{+}$ATPase e níveis de peroxidação lipídica. Observou-se diminuição dos níveis de glicogênio, proteínas, lipídios, triglicerídeos e $\mathrm{Na}^{+} / \mathrm{K}^{+}$ATPase, e aumento dos níveis de peroxidação lipídica.

$\mathrm{O}$ risco de efeitos adversos à saúde humana relacionados à exposição por pesticidas depende fundamentalmente do perfil toxicológico do produto, do tipo e da intensidade da exposição e da susceptibilidade da população exposta (DELGADO; PAUMGARTTEN, 2004).

Exposições curtas podem levar a conseqüências graves no ciclo de vida dos animais, mesmo que o composto não permaneça por tempo prolongado no local originalmente aplicado (DUTRA et al., 2009). Em decorrência do seu uso disseminado, existe o potencial de lesão imediata e/ou tardia para seres humanos, animais domésticos e vida selvagem, já que pode ocorrer a permanência de resíduos no ambiente aquático por tempo indeterminado, tendo assim grande influência na população de peixes durante anos (ARIAS et al., 2007).

A metodologia de Cromatografia em Camada Delgada (CCD) é uma técnica qualitativa de triagem, realizada com o objetivo de verificar a presença ou não de determinados resíduos, como o organofosforado e o carbamato. Como complementação à $\mathrm{CCD}$, podese fazer uma análise confirmatória quantitativa, por Cromatografia Gasosa, para que haja a posterior avaliação dos níveis de resíduos e se os mesmos estão de acordo com os Limites Máximos de Resíduos (LMR) preconizados pelo Codex Alimentarius, porem, é uma técnica que demanda custo operacional e equipamento mais sofisticado.

A CCD é uma técnica padrão confiável e de baixo custo que pode servir para determinar o grau de contaminação que pode estar ocorrendo e nortear futuras pesquisas com outras análises laboratoriais mais complexas.

\section{Conclusões}

Os resultados encontrados na metodologia de CCD nos alerta para a contaminação de uma fonte protéica muito importante que são os peixes, especificamente neste caso as Tilápias do Nilo $(O$. niloticus), criadas objetivando o consumo humano.

Os resultados servem de alerta para que outros estudos sejam realizados, avaliando assim a possibilidade de ocorrência de problemas de saúde pública, já que estes frigoríficos são de grande importância econômica em seus lugares de atuação, sendo que um deles possui o Serviço de Inspeção Federal (SIF) que o autoriza a comercializar este produto dentro de todo o território nacional.

\section{Agradecimentos}

Agradeço a todos que ajudaram na realização deste trabalho, especialmente à Aparecida Maria de Oliveira, e Márcia Sassahara. 


\section{Referências}

ADAMS, H. R. Farmacologia Colinérgica: agentes bloqueadores neuromusculares. In: BOOTH, N. H.; McDONALD, L. E. (Ed.). Farmacologia e Terapêutica em Veterinária. 6. ed. Rio de Janeiro: Guanabara Koogan, 1992. p. 111-114.

ARIAS, A. R. L.; BUSS, D. F.; ALBURQUERQUE, C.; INÁCIO, A. F.; FREIRE, M. M.; EGLER, M.; MUGNAI, R.; BAPTISTA, D. F. Utilização de bioindicadores na avaliação de impacto e no monitoramento da contaminação de rios e córregos por agrotóxicos. Ciência \& Saúde Coletiva, Rio de Janeiro, v. 12, n. 1, p. 61-72, 2007.

BIDLEMAN, T. F. Atmospheric transport and air-surface exchange of pesticides. Water, Air, and Soil Pollution, Dordrecht, v. 115, n. 1/4, p. 115-166, 1999.

DELGADO, I. F.; PAUMGARTTEN, F. J. R. Intoxicações e uso de pesticidas por agricultores do município de Paty do Alferes, Rio de Janeiro, Brasil. Cadernos de Saúde Pública, Rio de Janeiro, v. 20, n. 1, p. 180-186, 2004.

DURMAZ, H.; SEVGILER, Y.; ÜNER, N. Tissue-specific antioxidative and neurotoxic responses to diazinon in Oreochromis niloticus. Pesticide Biochemistry and Physiology, San Diego, v. 84, n. 3, p. 215-226, 2006.

DUTRA, B. K.; FERNANDES, F. A.; LAUFFER, A. L.; OLIVEIRA, G. T. Carbofuran-induced alterations in the energy metabolism and reproductive behaviors of Hyalella castroi (Crustacea, Amphipoda). Comparative Biochemistry and Physiology Part C, New York, v. 149, n. 4, p. 640-646, 2009.

DUTRA, B. K.; FERNANDES, F. A.; OLIVEIRA, G. T. Carbofuran-induced alterations in biochemical composition, lipoperoxidation, and $\mathrm{Na}^{+} / \mathrm{K}^{+}$ATPase activity of Hyalella Pleocuta and Hyalella curvispina in bioassays. Comparative Biochemistry and Physiology Part C, New York, v. 147, n. 2, p. 179-188, 2008.

DUTTA, H. M.; ARENDS, D. A. Effects of endosulfan on brain acetycholinesterase activity in juvenile bluegill sunfish. Environmental Research, San Diego, v. 91, n. 3, p. 157-162, 2003.

ELSER, J. J.; KIMMEL, B. L. Nutrient availability for phytoplankton production in a multiple impoundment series. Canadian Journal of Fisheries Aquatic Sciences, Ottawa, v. 42, n. 8, p. 1359-1370, 1985.

GIRÓN-PÉREZ, M. I.; SANTERRE, A.; GONZALEZJAIME, F.; CASAS-SOLIS, J.; HERNANDÉZCORONADO, M.; PEREGRINA-SANDOVAL， J.;
TAKEMURA, A.; ZAITSEVA, G. Immunotoxicity and hepatic function evaluation in Nile tilapia (Oreochromis niloticus) exposed to diazinon. Fish and Shellfish Immunology, London, v. 23, n. 4, p. 760-769, 2007.

HEJDUK, J.; SVOBODOVA, Z. Acute toxicity of carbamate based pesticides for fish. Acta Veterinaria Brno, Tchecoslovaquia, v. 49, n. 3/4, p. 251-257, 1980.

MARTÍNEZ-VIDAL，J. L.; GONZÁLES，F. J. E.; GLASS, C. R.; GALERA, M. M.; CANO, M. L. C. Análisis of lindane, $\mathrm{a}$ - and $\mathrm{b}$ - endosulfan and endosuefan sulfate in grenhouse air by gas chromatography Journal of Chromatography A, Amsterdam, v. 765, n. 1, p. 99108, 1997.

MINELLI, E. V.; RIBEIRO, M. L. Quantitative method for determination of organochorine in serum. Journal of Analytical Toxicology, Niles, v. 20, n. 1, p. 23-26, jan/ fev, 1996.

MORAES, E. C. F. Manual de toxicologia analítica. São Paulo: Roca, 1991.

RACKE, K. D. Degradation of organophosphorus insecticides in environmental matrices. In: CHAMBERS, J. E.; LEVI, P. E. (Ed.). Organophosphates: chemistry, fate and effects. San Diego: Academic Press, 1992. p. 4778 .

SARTOR, I. F.; SANTARÉM, V. A. Agentes empregados no controle de ectoparasitos. In: SPINOSA, $\mathrm{H}$. S.; GÓRNIAK, S. L.; BERNARDI, M. M. (Org.). Farmacologia aplicada a medicina veterinária. 4 . ed. Rio de Janeiro: Guanabara Koogan, 2006. p. 567-583.

SOUMIS, N.; LUCOTTE, M.; SAMPAIO. D.; ALMEIDA. D. C.; GIROUX. D.; MORAIS. S.; PICHET. P. Presence of Organophosphate insecticides in Fish of the Amazon River. Acta Amazonica, Manaus, v. 33, n. 2, p. 325-335, 2003.

STREIT, B. Bioaccumulation of contaminants in fish. In: BRAUNBECK, T.; HINTON, D.E.; STREIT, B. (Ed.). Fish ecotoxicology. Basel: Birkhauser, 1998. p. 353387.

ÜNER, N.; ORUÇ, E. Ö.; SEVGILER, Y.; SAHIN, N.; DURMAZ, H.; USTA, D. Effects os diazinon on acetylcholinesterase activity and lipid peroxidation in the brain of Oreochromis niloticus. Enviromental Toxicology and Pharmacology, Amsterdam, v. 21, n. 3, p. 241-245, 2006.

VAN DIJK, H. F. G.; GUICHERIT, R. Atmospheric dispersion of current-use pesticides: A review of the evidence from monitoring studies. Water, Air, and Soil Pollution, Dordrecht, v. 115, n. 1/4, p. 21-70, 1999. 
